\title{
Study on denitration performance of multi element modified MIL-101 (Fe) at low temperature
}

\author{
Shuqin Wang ${ }^{1,2, *}$, Xiaoxue $\mathrm{Li}^{1}$, and Jinjin $\mathrm{Wu}^{1}$ \\ ${ }^{1}$ Hebei Key Lab of Power Plant Flue Gas Multi-Pollutants Control, Department of Environmental \\ Science and Engineering, North China Electric Power University, Baoding 071003, China \\ ${ }^{2}$ Key Laboratory of Regional Energy System Optimization of Ministry of Education, North China \\ Electric Power University, Beijing 100084, China
}

\begin{abstract}
MIL-101 (Fe) was modified by amino group and doped by $\mathrm{Cu}$ and Co elements by microwave hydrothermal method. The effect of SCR denitrification at low temperature was investigated with high concentration of NOx as adsorption object. The results show that when the flue gas temperature is $200{ }^{\circ} \mathrm{C}$ and the NOx concentration is up to $1640 \mathrm{mg} / \mathrm{m}^{3}$, the removal efficiency of NOx can reach $86 \%$ under the optimal conditions, which is 1.5 times higher than that before modification. In addition, the characterization results indicated that the specific surface area of the modified catalyst increased, the thermal stability was good at low temperature, the selective adsorption capacity of $\mathrm{NO}$ was enhanced, and the doping played a synergistic catalytic role. It can be used for flue gas denitration in various industries.
\end{abstract}

\section{Introduction}

MIL-101 series is one of the second generation MOFs materials. Because of its super large specific surface area, high stability and easy surface functionalization, it has become a research hotspot in the field of adsorption [1,2]. For the sake of improve the adsorption and selectivity of MOFs materials to adapt to more actual flue gas, metal elements are usually used to modify MOFs materials [3-5]. The MOFs with modified bimetallic sites prepared by Yao Zhuo [6] showed a good catalytic denitration effect when the NOx concentration was less than $670 \mathrm{mg} / \mathrm{m}^{3}$ at about $240{ }^{\circ} \mathrm{C}$, and the conversion efficiency was only about $55 \%$ at $200{ }^{\circ} \mathrm{C}$. Although the conversion efficiency of mil series materials modified by Wang Peng [7] is about $90 \%$ when the NOx concentration is lower than $670 \mathrm{mg} / \mathrm{m}^{3}$ at $200{ }^{\circ} \mathrm{C}$, it is unknown whether the conversion efficiency of high concentration NOx can reach the same high. In addition, functionalized MOFs can be achieved by introducing specific functional groups such as $-\mathrm{NH}_{2},-\mathrm{COOH}$ and $-\mathrm{OH}$ [8]. Therefore, it is possible to improve the denitration efficiency at high concentration by optimizing the structure and properties of MIL-101 (Fe) monomer with appropriate modification methods.

* Corresponding author: wsqhg@163.com 
Compared with hydrothermal method, microwave hydrothermal method can greatly shorten the preparation time. Therefore, in this study, microwave hydrothermal method was used to prepare multi-component modified MIL-101 (Fe) material to realize SCR denitration at high concentration and low temperature.

\section{Materials and methods}

\subsection{Chemicals}

Anhydrous ethanol (AR), glacial acetic acid (AR), terephthalic acid (AR), N, Ndimethylformamide (AR), 2-Aminoterephthalic acid (AR), copper nitrate trihydrate (AR), cobalt nitrate hexahydrate (AR), N - (1-naphthyl) ethylenediamine hydrochloride (AR), ferric chloride (AR).

\subsection{Materials}

MIL-101 (Fe) was synthesized from terephthalic acid, N, N-dimethylformamide and $\mathrm{FeCl}_{3}$ by microwave hydrothermal method.

$\mathrm{NH}_{2}$-MIL-101(Fe) can be obtained by replacing terephthalic acid with 2Aminoterephthalic acid during the preparation of MIL-101 (Fe). In addition, copper nitrate or cobalt nitrate were added before stirring for $30 \mathrm{~min}$. For example, $\mathrm{xCu}-\mathrm{NH}_{2}-\mathrm{MIL}-101$ (x\% is the mole percentage of $\mathrm{Cu}$ or $\mathrm{Co}$ and $\mathrm{Fe}$ ) is used to express the product.

\subsection{Characterization}

The specific surface area, pore size distribution and structural characteristics of the samples were detected by using the SA3100 specific surface area and porosity analyzer of Beckman Coulter Co., Ltd.The thermal stability of the samples was analyzed using the TGA 4000 thermogravimetric analyzer of Birkin Elmer Instruments.; Infrared test was carried out using the Tensor II Fourier transform infrared spectrometer of Brock Technologies Co., Ltd. to analyze the presence of groups and elements in the sample; The NO adsorption strength of the catalyst was analyzed and detected by the PCA-1200 detector (NO-TPD) of Beijing Piod Electronic Technology Co., Ltd.

\subsection{Activity evaluation}

During the experiment, the ventilation rate of $\mathrm{N}_{2}: 180 \mathrm{~mL} / \mathrm{min}$, the ventilation rate of $\mathrm{NO}$ : $60 \mathrm{~mL} / \mathrm{min}$, the ventilation rate of $\mathrm{O}_{2}: 10 \mathrm{~mL} / \mathrm{min}$, and the temperature was set at $200{ }^{\circ} \mathrm{C}$. To explore the influence of the initial concentration of NOx on the denitrification effect, the nitrogen ventilation rate was controlled to make the concentration change in $500 \sim 2400 \mathrm{mg} /$ $\mathrm{m}^{3}$. In the experiment, $0.5 \mathrm{~g}$ catalyst sample was sampled for $15 \mathrm{~min}$. The concentration of each gas after reaction was determined by spectrophotometry with naphthalene ethylenediamine hydrochloride. The denitration efficiency of the sample was calculated by combining with the initial value. 


\section{Results}

\subsection{Denitration efficiency of catalyst materials}

Table 1. Denitration efficiency under different modification conditions.

\begin{tabular}{ccccc}
\hline Sample & & $\begin{array}{c}\text { NO removal } \\
\text { efficiency } \\
(\%)\end{array}$ & $\begin{array}{c}\mathrm{NO}_{2} \text { removal } \\
\text { efficiency } \\
(\%)\end{array}$ & $\begin{array}{c}\text { NOx removal } \\
\text { efficiency } \\
(\%)\end{array}$ \\
\hline MIL-101(Fe) & & 22 & 44 & 34 \\
$\mathrm{NH}_{2}-\mathrm{MIL}-101(\mathrm{Fe})$ & & 51 & 70 & 55 \\
$\mathrm{NH}_{2}-\mathrm{Cu}(\mathrm{x} \%)-\mathrm{MIL}-$ & $\mathrm{x}=3$ & 69 & 76 & 71 \\
$101(\mathrm{Fe})$ & $\mathrm{x}=7$ & 63 & 89 & 74 \\
& $\mathrm{x}=9$ & 59 & 90 & 70 \\
$\mathrm{NH}_{2}-\mathrm{Cu}(5 \%)-\mathrm{Co}(\mathrm{x} \%)-$ & $\mathrm{x}=3$ & 70 & 81 & 64 \\
$\mathrm{MIL}-101(\mathrm{Fe})$ & $\mathrm{x}=5$ & 72 & 91 & 80 \\
& $\mathrm{x}=7$ & 73 & 76 & 75 \\
\end{tabular}

The denitration efficiency of catalyst materials before and after modification is shown in Table 1. After the introduction of amino and doping elements, the denitration efficiency is obviously better than that of MIL-101(Fe) monomer. The denitration efficiency of Co and $\mathrm{Cu}$ double doped catalyst is obviously better than that of $\mathrm{Cu}$ Single doped catalyst. When the Co doping ratio is $1 \%$, the catalyst has the highest denitration efficiency, the removal efficiency of NO is more than $75 \%$, the removal efficiency of total nitrogen oxides is $80 \%$, and the removal efficiency of $\mathrm{NO}_{2}$ is more than $90 \%$. Therefore, $\mathrm{NH}_{2}-\mathrm{Cu}(5 \%)$-Co (1\%)MIL-101 (Fe) is the best catalyst for denitration.

\subsection{Effect of NOx initial concentration on denitration efficiency}

The initial concentration of NOx was in the range of $500 \sim 2400 \mathrm{mg} / \mathrm{m}^{3}$ by adjusting the ventilation rate of $\mathrm{NO}$ and $\mathrm{N}_{2}$. In this range, the denitration efficiency of the catalyst increases with the increase of the initial concentration of NOx, and the highest denitration efficiency reaches $83 \%$ when the initial concentration of NOx reaches $2100 \mathrm{mg} / \mathrm{m}^{3}$. Overall, the denitration efficiency of $\mathrm{NH}_{2}-\mathrm{Cu}(5 \%)-\mathrm{Co}(1 \%)-\mathrm{MIL}-101(\mathrm{Fe})$ is more than $70 \%$, indicating that the modified catalyst has good adaptability to low concentration and high concentration of NOx, and is suitable for flue gas denitration in many industries.

\subsection{The influence of continuous use time on denitrification efficiency}

Table 2. Effect of continuous use time on denitration efficiency of MOFs materials.

\begin{tabular}{cccc}
\hline $\begin{array}{c}\text { Continuous use } \\
\text { time }(\min )\end{array}$ & $\begin{array}{c}\text { NO removal } \\
\text { efficiency }(\%)\end{array}$ & $\begin{array}{c}\mathrm{NO}_{2} \text { removal } \\
\text { efficiency }(\%)\end{array}$ & $\begin{array}{c}\text { NOx removal } \\
\text { efficiency }(\%)\end{array}$ \\
\hline 20 & 81 & 97 & 86 \\
40 & 74 & 93 & 81 \\
60 & 70 & 86 & 75 \\
\hline
\end{tabular}

The experimental results are shown in Table 2. After continuous use for 1 hour, the NOx removal efficiency only decreases by $11 \%$, and the denitration efficiency can still reach more than $70 \%$. The main reason for the decrease of denitration efficiency may be that the catalyst adsorbs a large amount of gas when it is used continuously at high temperature, which affects 
its adsorption performance. Generally speaking, $\mathrm{NH}_{2}-\mathrm{Cu}(5 \%)-\mathrm{Co}(1 \%)-\mathrm{MIL}-101(\mathrm{Fe})$ catalyst has good continuous performance.

\subsection{Catalyst anti-interference experiment}

In the experiment, pure $\mathrm{CO}_{2}$ and pure $1 \% \mathrm{SO}_{2}$ were introduced respectively. Under the influence of high concentration of $\mathrm{CO}_{2}$, the removal efficiency of total nitrogen oxides was higher than $80 \%$. When the concentration of $\mathrm{SO}_{2}$ reaches $2280 \mathrm{mg} / \mathrm{m}^{3}$, the removal rate of $\mathrm{NO}_{2}$ is still higher than $80 \%$; The total denitration efficiency is still over $70 \%$. Therefore, the modified catalyst has good ability to resist the interference of $\mathrm{CO}_{2}$ and $\mathrm{SO}_{2}$.

\subsection{BET characterization}

Table 3. Analysis of BET of MOFs.

\begin{tabular}{cccc}
\hline Sample & $\begin{array}{c}\text { BET surface area } \\
\left(\mathrm{m}^{2} \cdot \mathrm{g}^{-1}\right)\end{array}$ & $\begin{array}{c}\text { Average aperture } \\
(\mathrm{nm})\end{array}$ & $\begin{array}{c}\text { Pore volume } \\
\left(\mathrm{cm}^{3} \cdot \mathrm{g}^{-1}\right)\end{array}$ \\
\hline $\begin{array}{c}\text { MIL-101(Fe) } \\
\text { NH } 2 \text {-MIL- }\end{array}$ & 190.19 & 2.30 & 0.11 \\
$\begin{array}{c}\text { 101(Fe) } \\
\mathrm{NH}_{2}-\mathrm{Cu}-\mathrm{MIL}-\end{array}$ & 300.75 & 12.98 & 0.33 \\
$\begin{array}{c}101(\mathrm{Fe}) \\
\mathrm{NH}_{2}-\mathrm{Cu}-\mathrm{Co}-\end{array}$ & 268.27 & 3.23 & 0.22 \\
MIL-101(Fe) & 260.91 & 2.67 & 0.17 \\
\hline
\end{tabular}

Table 3 shows the surface structure parameters of the samples. The BET specific surface area of MIL-101 was $190.19 \mathrm{~m}^{2} / \mathrm{g}$, and the specific surface area of amino modified catalyst was increased to $300.75 \mathrm{~m}^{2} / \mathrm{g}$. When the specific surface area of bimetallic element doped catalyst was similar, more active sites were provided to promote the catalytic reaction. Therefore, the surface structure of the prepared modified MOFs catalyst is better.

\subsection{TGA characterization}

The results of thermogravimetric treatment are shown in Figure 1. The quality of the four catalysts decreased in the same way in nitrogen atmosphere, so the modification had little effect on the thermal stability of the catalysts. The first weight loss of the four catalysts at about $150{ }^{\circ} \mathrm{C}$ is mainly due to the loss of a small amount of anhydrous ethanol and water in the catalyst. The catalyst was dried at $80{ }^{\circ} \mathrm{C}$ before use, so the weight loss was less, about $5 \%$. The second stage of weight loss occurs between $150{ }^{\circ} \mathrm{C}$ and $300{ }^{\circ} \mathrm{C}$. The boiling point of DMF is $152.8{ }^{\circ} \mathrm{C}$, so DMF is desorbed after $150{ }^{\circ} \mathrm{C}$. The solvent used in the reaction process of catalyst preparation is pure DMF, which is difficult to remove. The unmodified catalyst may be DMF in the catalyst at this stage, while the modified catalyst may also have low temperature decomposition of $-\mathrm{NH}_{2}$ group at this stage [9]. The third stage is $300{ }^{\circ} \mathrm{C} \sim$ $500{ }^{\circ} \mathrm{C}$. In this stage, the quality of the catalyst decreases sharply, mainly because the main framework of the catalyst begins to collapse and the organic structure decomposes rapidly. Therefore, the catalyst prepared in this paper has good thermal stability, which is suitable for denitration reaction below $300{ }^{\circ} \mathrm{C}$, and has a wide range of applications [10]. 


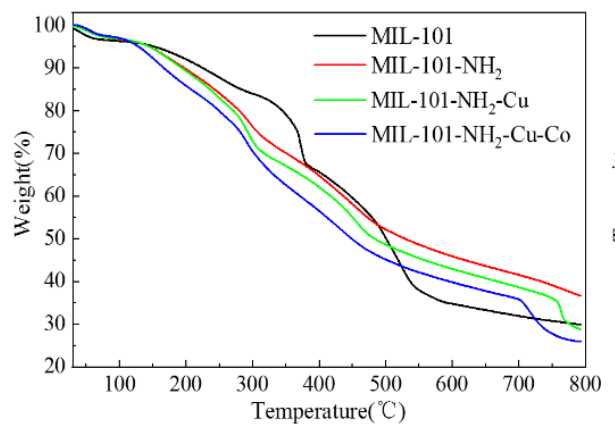

Fig. 1. Analysis of TGA of MOFs.

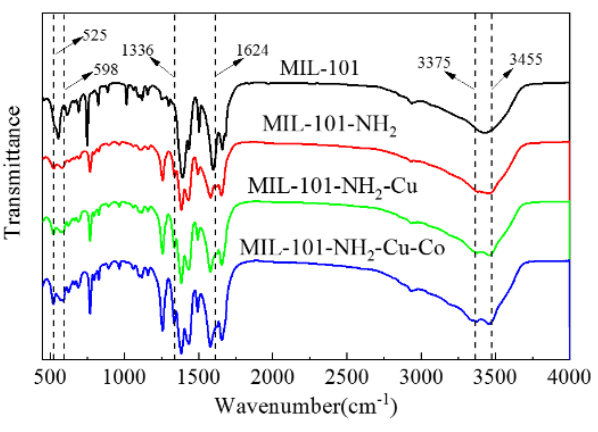

Fig. 2. Analysis of FTIR of MOF.

\subsection{FTIR characterization}

Four kinds of catalyst samples were tested and analyzed by infrared spectroscopy. It can be seen from Figure 2 that the infrared spectra of three kinds of modified catalysts are basically consistent with those of unmodified catalysts due to the extremely low metal content in the modified catalysts, which indicates that the prepared MIL-101 catalysts are basically consistent. $\mathrm{NH}_{2}$-MIL-101 has several more peaks than MIL-101, among which $3455 \mathrm{~cm}^{-1}$ and $3375 \mathrm{~cm}^{-1}$ are symmetrical stretching vibration peaks and asymmetric stretching vibration peaks $[11,12], 1624 \mathrm{~cm}^{-1}$ is bending vibration peak of $\mathrm{N}-\mathrm{H}$ bond caused by $\mathrm{NH}_{2}$ group vibration, and $1336 \mathrm{~cm}^{-1}$ is stretching vibration absorption peak of $\mathrm{C}=\mathrm{N}$ bond in catalyst $[13$, 14]. The results showed that there was $-\mathrm{NH}_{2}$ group on the surface of the catalyst, and the amino modified MIL-101 catalyst was successfully prepared. The vibration absorption peaks at $598 \mathrm{~cm}^{-1}$ and $525 \mathrm{~cm}^{-1}$ should be the presence of $\mathrm{Cu}$ in the catalyst, corresponding to the peaks related to $\mathrm{Cu}$ coordination in the catalyst structure [15].

\subsection{NO-TPD characterization}

In order to explore the adsorption performance of NO on the catalyst surface, NO-TPD tests were carried out on four kinds of catalysts, and the test results are shown in Figure 3. When the temperature is lower than $250{ }^{\circ} \mathrm{C}, \mathrm{NH}_{2}$-MIL-101 and $\mathrm{NH}_{2}$-Cu-Co-MIL-101 both have a no desorption peak, while unmodified MIL-101 has no desorption peak, which indicates that the adsorption capacity of modified catalyst for $\mathrm{NO}$ is improved. The desorption peak of $\mathrm{NH}_{2}$-MIL-101 for $\mathrm{NO}$ is $119.7{ }^{\circ} \mathrm{C}$, while the desorption peak of $\mathrm{NH}_{2}-\mathrm{Cu}-\mathrm{Co}-\mathrm{MIL}-101$ is about $178.8{ }^{\circ} \mathrm{C}$, which indicates that a new low-temperature $\mathrm{NO}$ adsorption site is added after modification, and the desorption temperature of the Catalyst Doped with $\mathrm{Cu}$ and $\mathrm{Co}$ increases, which indicates that the adsorption strength of the Catalyst Doped with $\mathrm{Cu}$ and $\mathrm{Co}$ increases. In addition, the peak area of the Catalyst Doped with $\mathrm{Cu}$ and $\mathrm{Co}$ is greatly increased, which indicates that doping $\mathrm{Cu}$ and $\mathrm{Co}$ can help to improve the ability of the catalyst to adsorb $\mathrm{NO}$ at low temperature, which is conducive to the activation of $\mathrm{NO}$ on the catalyst surface and the low-temperature SCR catalytic reaction [16]. 


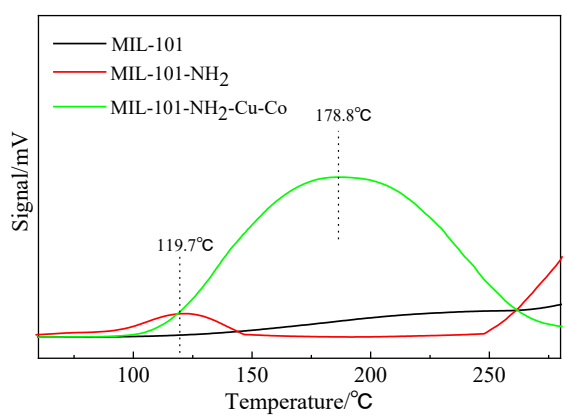

Fig. 3. NO-TPD analysis of MOF.

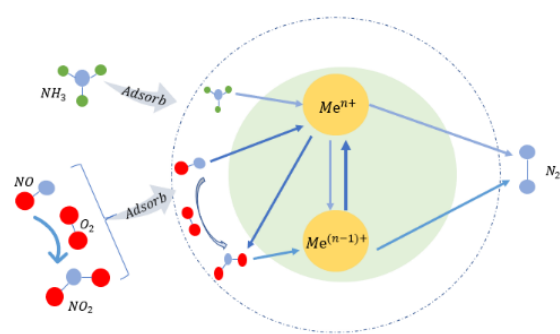

Fig. 4. Process of adsorption and catalysis.

\section{Adsorption mechanism}

According to the FTIR spectra and bet characterization results, amino groups were successfully introduced and the adsorption performance was improved mainly by increasing the specific surface area of the catalyst. From the experimental results of denitration efficiency before and after modification, it can be inferred that $\mathrm{Fe}^{3+}$ in the synthesized MIL$101(\mathrm{Fe})$ catalyst material is the active center, and the doping of $\mathrm{Cu}$ and $\mathrm{Co}$ may occupy part of $\mathrm{Fe}^{3+}$ active center, so the catalytic activity of the modified sample is different. However, when the molar ratio of $\mathrm{Cu}$ and $\mathrm{Co}$ doping exceeds $5 \%$ and $1 \%$ respectively, the denitration efficiency decreases, which also shows that the key role is still the active host $\mathrm{Fe}^{3+}, \mathrm{Cu}^{2+}$ and $\mathrm{Co}^{2+}$ only play the role of modification and synergistic catalysis, which is consistent with the literature report $[17,18]$ on SCR denitration.

It can be inferred that the SCR catalytic Denitration Process of iron-based MIL-101 catalyst is as follows: $\mathrm{NH}_{3}, \mathrm{O}_{2}$ and $\mathrm{NO}$ are adsorbed on the catalyst surface, $\mathrm{O}_{2}$ oxidizes part of no to $\mathrm{NO}_{2}, \mathrm{Fe}^{3+}$ catalyzes part of $\mathrm{NO}$ to $\mathrm{NO}_{2}, \mathrm{NH}_{3}$ to $\mathrm{N}_{2}$. In this process, $\mathrm{Fe}^{3+}$ coordination unsaturated site will be reduced to $\mathrm{Fe}^{2+}$ coordination unsaturated site, $\mathrm{Fe}^{2+}$ will reduce $\mathrm{NO}_{2}$ and $\mathrm{NO}$ to $\mathrm{N}_{2}$, and then $\mathrm{Fe}^{2+}$ can be oxidized to $\mathrm{Fe}^{3+}$ again by $\mathrm{O}_{2}$. The results of bet showed that $\mathrm{Cu}$ and $\mathrm{Co}$ were successfully doped. Combined with NO-TPD analysis, the doping of $\mathrm{Cu}$ and $\mathrm{Co}$ enhanced the NO adsorption performance of the catalyst, and could cooperate with $\mathrm{Fe}^{3+}$. The valence state of $\mathrm{Cu}$ changed between +1 and +2 , and that of Co changed between +2 and +3 , which was consistent with the description of related literature $[18,19]$.

The adsorption catalysis process is shown in Figure 4. In addition, according to the experimental data in Figure 4, As the concentration of NOx increases, the denitration efficiency of SCR reaction is improved. The NO-TPD characterization analysis diagram also proves that the adsorption strength of NO on the catalyst surface is a key factor affecting SCR reaction, indicating that adsorption is the speed control step of the whole adsorption catalytic reaction

\section{Conclusion}

The samples of multicomponent modified MIL-101 (Fe) catalyst were prepared by microwave hydrothermal method. The results show that the best catalyst is $\mathrm{NH}_{2}-\mathrm{Cu}(5 \%)$ $\mathrm{Co}(1 \%)$-MIL-101 (Fe). When the reaction temperature is $200{ }^{\circ} \mathrm{C}$ and the initial concentration of NOx is $1640 \mathrm{mg} / \mathrm{m}^{3}$, the NOx removal rate can reach $86 \%$, which is 1.5 times higher than that before modification, and the nitrogen removal performance is significantly improved at high concentration. The continuous service time of the modified catalyst is prolonged, and it has excellent anti-interference performance. The characterization results showed that the 
modification of amino group was mainly to increase the specific surface area of the catalyst and enhance its adsorption capacity. The doping of metal elements increased the number of active sites and improved the adsorption capacity of NO, which was consistent with the experimental results. Mechanism analysis also shows that adsorption is the speed control step of SCR denitration process.

The project was supported by the National Basic Research Program of China(2018YFB060420103)

\section{References}

1. C. Kaifei. Master's Degree Thesis of Zhengzhou University (2019)

2. J. Jiahui. Master's Degree Thesis of Hunan University (2019)

3. A. Imteaz, J. Sung Hwa. Chemical Engineering Journal 251,35-42(2014)

4. Z. Wei, L. Peijue, X. Shuning, et al. Applied Catalysis B: Environmental 172-173, 4651(2015)

5. G. Kranthi Kumar, M. Suresh, M. Saratchandra Babu, et al. Inorganica Chimica Acta 446, 61-74(2016)

6. Y. Zhuo,Q. Dianli,G. Yuxiang,et al. Journal of Synthetic Crystals 48(04), 682686+692(2019)

7. W. Peng, S. Hong, Q. Xie, et al. Journal of Hazardous Materials 301, 512-521(2016)

8. J. An, J G S, L. Rosi Nathaniel. Journal of the American Chemical Society 131(24)(2009)

9. P. Serra-Crespo, A.Van Der Veen M, E. Gobechiya, et al. J Am Chem Soc 134(20),83148317(2012)

10. X. Shunji, Z. Qinghong, L. Guodong, et al. Chemical Communications 52(1): 3559(2016)

11. V. Tuan A, L. Giang H, D. Canh D, et al. RSC Adv 4(78), 41185-41194(2014)

12. P. Yanqing, S. Gonghua, R. Dou. Green Chemistry 8(6),573-575(2006)

13. S. Lijuan, L. Sshijing, W. Weiming, et al. Dalton Transactions 42(37)(2013).

14. B. Salete S, G. Carlos M, B. Andre D S, et al. Catalysis Today 210, 142-148(2013)

15. B. Elisa, M. Sara, G. Diego, et al. The Journal of Physical Chemistry C 116(37), 1983919850(2012)

16. S. Jinru,W. Ying,M. Qiang,et al. Journal of Fuel Chemistry and Technology 48(02), 197204(2020)

17. L. Zhenzhen. Master's Degree Thesis of Dalian University of Technology (2016)

18. W. Peng. Master's Degree Thesis of Dalian University of Technology(2016)

19. W. Yuan, Z Li, L. Ren, et al. Chemical Engineering Journal 381(2020) 